\title{
Wear Compensation Model Based on the Theory of Archard and Definite Integral Method
}

\author{
Pei-Feng Niu ${ }^{1,2}$ and Bao-Liang Tian ${ }_{(D)}^{1,2}$ \\ ${ }^{1}$ Key Lab of Industrial Computer Control Engineering, Yanshan University, Qinhuangdao 066004, China \\ ${ }^{2}$ National Engineering Research Center for Equipment and Technology of Cold Strip Rolling, Qinhuangdao 066004, China \\ Correspondence should be addressed to Bao-Liang Tian; 125708047@qq.com
}

Received 30 August 2017; Accepted 1 February 2018; Published 12 March 2018

Academic Editor: Denis Benasciutti

Copyright (c) 2018 Pei-Feng Niu and Bao-Liang Tian. This is an open access article distributed under the Creative Commons Attribution License, which permits unrestricted use, distribution, and reproduction in any medium, provided the original work is properly cited.

\begin{abstract}
Aiming at low accuracy control of the flatness measuring system in cold rolling process, the wear of measuring rings of the flatness measuring roll is an important factor, which affects the flatness measurement accuracy and the strip quality. When the radial pressure and the width of the strip change, the wear thickness of the different measuring rings is also changed, which seriously increased the deviation between measured values and actual values. For thirty-eight measuring rings of flatness measuring roll, it is important to establish an accurate wear compensation model for each measuring ring to improve the measurement accuracy of the online flatness control model. Wear compensation model is established by the theory of Archard, definite integral method, and weighted coefficient method, and the data of the rolling length, strip width, and the radial force of the six million tons' strip are used to analyze and discuss the wear compensation model of flatness measuring roll. The experiment result shows that the flatness control accuracy is improved effectively and the better strip shape can be achieved.
\end{abstract}

\section{Introduction}

As we all know, the quality of the strip is mainly evaluated by the flatness of strip [1-3]. The strip would be inherently stronger and easier to use if it had uniform width and thickness along the axial direction when rolled. However, many factors have effects on the strip flatness so that it is hard to achieve this ideal. If the incoming strip is perfectly flat, the gap between the work rolls will be expected to be precisely parallel. Unfortunately, the work rolls with high force lead the strip to bend and create a nonparallel roll gap across the width of the strip.

The flatness measured values and the pressure distribution values are affected by the wear of the measuring rings of the flatness measuring roll, and the rolling process also generates heat which causes uneven thermal expansion of the flatness measuring roll. Recently, a researcher focused on a coordinate measuring machine, which was used for the selection of sampling points for accurate evaluation of flatness deviation [4]. The various friction conditions at different locations along the contact area between the rolls and the foil were discussed to improve strip quality [5]. In a later study, a factorial analysis had been employed to study the effect that tension leveling process parameters had on the shape characteristics of the leveled product [6]. The transfer matrix set up by GA-BP (Genetic Algorithm-Backpropagation) network model was successfully applied into the flatness control system which provided a theoretical framework for flatness control [7]. The model of strip profile and related flatness involving a novel combination of beam finite elements with multiple coupled Winkler elastic foundations were improved accurately for achieving high quality flat-rolled products [8]. In addition, the influences of the measuring deviation of the strip edges, the deflection of flatness measuring roll, and the shape of the coil on the shape measuring results were discussed [9]. Temperature distribution along the thickness of strip was analyzed during cooling process [10]. In recent years, a deflection model for the flatness measuring roll was 


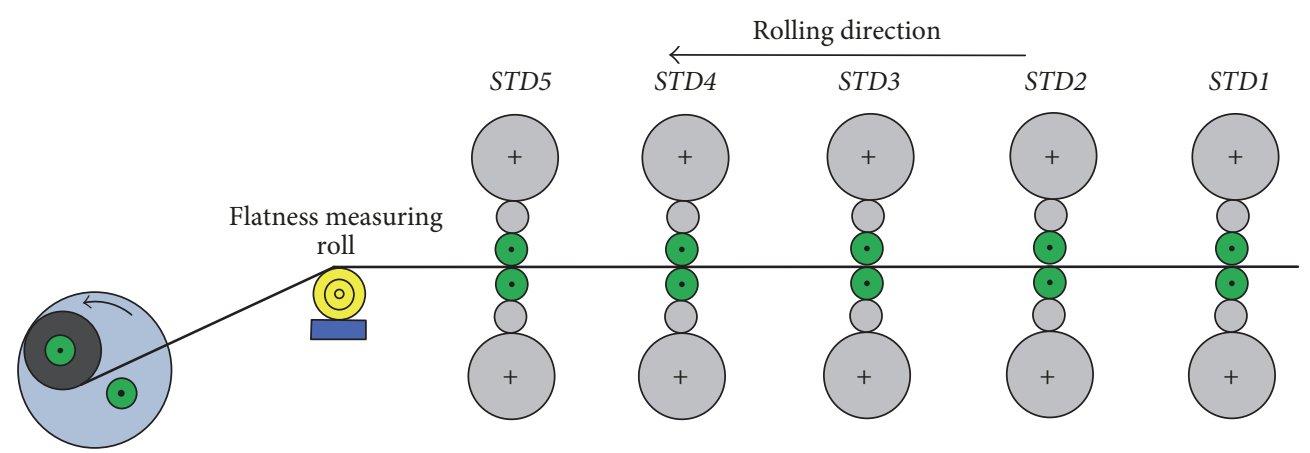

FIGURE 1: Distribution layout diagram of continuous rolling mill.

obtained by using the influence function method [11]. The cubic patterns were introduced on the basis of the traditional linear, quadratic, and quadratic flatness basic patterns [12]. The mathematical model of flatness error minimum zone solution was formulated and an improved genetic algorithm was discussed to implement flatness error minimum zone evaluation [13]. Many scholars had done a deep research on how to improve the shape quality [14-16]. However, the point that the flatness measurement accuracy is affected by the wear of measuring rings of flatness measuring roll is not discussed.

In the cold strip rolling process, the strip flatness is major indicator to evaluate quantity of strip. The flatness values are detected by flatness measuring roll at the last roll stand exit in Figure 1.

There are five stand-alone rolling mills, each consisting of a pair of working rolls, a pair of intermediate rolls, and a pair of support rolls, and the flatness measuring roll is mounted between the coiler and the mill outlet. The contact surface between strip and flatness measuring roll produces a certain amount of wear on the surface of measuring rings of flatness measuring roll. The online flatness measuring results may be distorted and cannot accurately give the true flatness values. Hence, the wear compensation model is needed to improve the strip flatness. Based on the wear calculated values, the effective wear compensation model is given to improve the strip flatness. When flatness measuring signal is transmitted to the shape control computer, the flatness measuring values are handled accurately by flatness control model.

When the wear compensation model is added to the flatness target curve, the measurement accuracy and the quality of strip are improved, and the economic benefit of enterprise has increased by the good strip. The wear of the measuring rings has effects on flatness measured values. So it is necessary to give correctly wear compensation model for flatness closed-loop feedback control system. Firstly, when flatness measurement signal is transmitted to the shape control computer, the flatness measured values are handled accurately by shape control model. Then, the measured results are researched in detail and the corresponding compensation model is established. Finally, the simulation calculation and analysis are carried out on a $1450 \mathrm{~mm}$ cold mill as an example, and some conclusions are obtained.

\section{Problem Description}

The flatness measuring roll has a steel core with four axial grooves, in which the magnetoelastic transducers are secured. The flatness measuring roll has 38 measuring rings, which can be divided into $26 \mathrm{~mm}$ or $52 \mathrm{~mm}$ wide measuring zones $(12 \times$ $26 \mathrm{~mm}+14 \times 52 \mathrm{~mm}+12 \times 26 \mathrm{~mm}$ ), and four transducers in each measuring zone are installed in the grooves. Hardened measuring rings are shrunk onto the steel core to protect the transducers. The measuring rings have a smooth surface and are sufficiently elastic to transmit the forces from the strip to the transducers. There are narrow gaps between the steel rings, so that each zone is measured separately. The steel rings are $10 \mathrm{~mm}$ thick with declension to permit $6 \mathrm{~mm}$ to be ground off the outside diameter for flatness measuring roll. The diameter of each measuring ring is $313 \mathrm{~mm}$, and the measuring rings are held in place by shrink-fitting and each transducer is subject to a preload of around $16 \mathrm{kN}$, as shown in Figure 2. The transducers are developed on the basis of the ABB (Asea Brown Boveri) press-conductor principle and it is necessary to ensure that the strength of the roll is not adversely affected. The construction of the transducer is similar to that of a transformer. The steel core comprises a number of plates and it is stamped out from a sheet metal with suitable magnetic properties. Under a mechanical load, the magnetic coupling between the primary and secondary winding will be changed more or less by mechanical load. All transducers are connected in series on the primary side. On the secondary side, the four transducers are connected in series for the measuring zone. The measuring ring in strip tension also reduces to an insignificant level the effect of temperature variations and centrifugal forces on the output signals, as shown in Figure 3.

When a constant strip speed is established in the cold strip rolling process, the flatness measuring roll is driven by the friction force between the strip and the flatness measuring roll. To reduce the strip from sliding over the measuring roll which may drop wear volume on the flatness measuring roll surface, the flatness measuring roll often needs to be driven by a special motor during acceleration and deceleration. A dead band in the speed control system reduces slipping between flatness measuring roll and strip even if the speed reference 


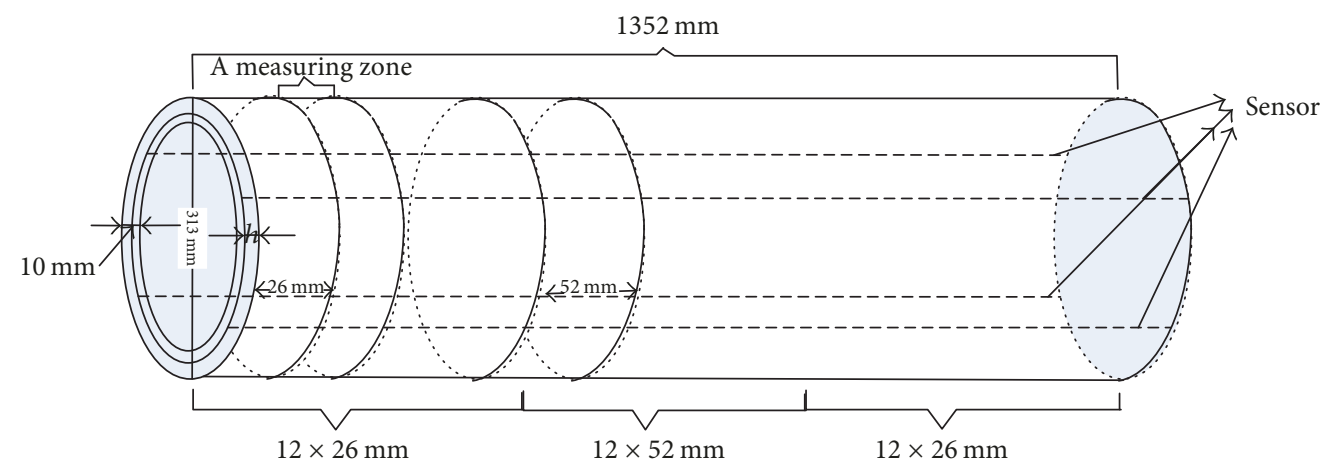

FIGURE 2: Transducer arrangement in flatness measuring roll.

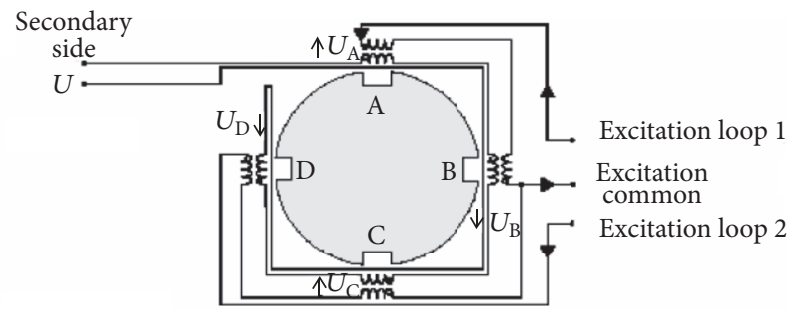

$\uparrow:$ Phase of voltage is $0^{\circ}$

$\downarrow$ : Phase of voltage is $180^{\circ}$

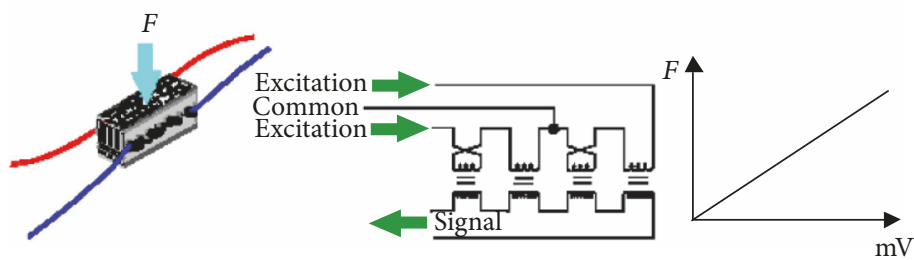

FIGURE 3: Trans and wiring diagram of a measuring zone.

is not precisely set. However, the wear between strip and flatness measuring roll is inevitable. The flatness measuring roll must be reground before the diameter difference between the center and the periphery rings reaches $1 \mathrm{~mm}$.

In the cold strip rolling process, the flatness measuring signal cannot truly reflect strip flatness because flatness measuring roll is frayed. There is a large measurement deviation between the actual values and the measured values. So establishment of cold strip online flatness wear compensation model is very important to improve precision of the flatness measuring and the quality of strip and it is necessary to give correct wear compensation model to shape closed-loop feedback control system.

\section{Establishment of Wear Compensation Model}

Considering the strip production process and the flatness measurement accuracy, the wear compensation model of the measuring rings is established by definite integral method [17-19], the theory of Archard [20], and weighted coefficient method. A large number of production data are used to verify the control accuracy of the wear compensation model. The experimental result is used to demonstrate that the wear compensation model can improve the target accuracy of online flatness measurement and the strip flatness.

In the long rolling process of strip, there will be a certain degree of wear and tear on the surface of the measuring rings of the flatness measuring roll. The online flatness measured values may be distorted and cannot give the true flatness measurement values because the radial force is changed by the wear of the measuring rings. For the analysis, there are many factors that have influence on the mechanical interface between flatness measuring roll and strip. The following factors have been considered and analyzed: radial force, rolling length, and strip width.

The abrasive wear equation of the $i$ th measuring ring is established by the theory of Archard [20], and the following formula is expressed as

$$
V_{i}(x)=\frac{K_{\mathrm{abr}} F_{i}(x) L}{H}
$$


where $V_{i}(x)$ is the $i$ th measuring ring volume removed of flatness measuring roll $\left(\mathrm{mm}^{3}\right), K_{\mathrm{abr}}=\Delta W / d p v t$ is the abrasive wear coefficient of measuring rings of flatness measuring roll $\left(\mathrm{cm}^{3} / \mathrm{N} \cdot \mathrm{m}\right), W$ is the weight loss $(\mathrm{g}), d$ is the material proportion $\left(\mathrm{g} / \mathrm{cm}^{3}\right), P$ is the test load $(\mathrm{N}), v$ is the sliding line velocity $(\mathrm{m} / \mathrm{s}), T$ is the wear time $(\mathrm{s}), F_{i}(x)$ is the radial force acting on the $i$ th measuring ring of flatness measuring roll $(\mathrm{kN}), L$ is the strip length rolled $(\mathrm{km})$, and $H$ is the ratio between strip and ring hardness of flatness measuring roll.

The definite integral method is applied for calculating the wear volume [17-19], and the total wear volume of measuring rings of flatness measuring roll is established.

$$
\begin{aligned}
\sum_{i=1}^{38} V_{i}(x)= & \sum_{i=1}^{12} \int_{313-h_{i}(x)}^{313} 26 \times 2 \pi x d x \\
& +\sum_{i=13}^{26} \int_{313-h_{i}(x)}^{313} 52 \times 2 \pi x d x \\
& +\sum_{i=27}^{38} \int_{313-h_{i}(x)}^{313} 26 \times 2 \pi x d x \\
= & 52 \pi \sum_{i=1}^{12} \int_{313-h_{i}(x)}^{313} x d x \\
& +104 \pi \sum_{i=13}^{26} \int_{313-h_{i}(x)}^{313} x d x \\
& +52 \pi \sum_{i=27}^{38} \int_{313-h_{i}(x)}^{313} x d x \\
= & 26 \pi \sum_{i=1}^{12}\left(626 h_{i}(x)-h_{i}(x)^{2}\right) \\
& +52 \pi \sum_{i=13}^{26}\left(626 h_{i}(x)-h_{i}(x)^{2}\right) \\
& +26 \pi \sum_{i=27}^{38}\left(626 h_{i}(x)-h_{i}(x)^{2}\right) .
\end{aligned}
$$

The total wear volume $\sum_{i=1}^{38} V_{i}(x)$ of measuring rings is equal to the sum of the wear volume of each measuring ring, where $h_{i}(x)$ is the wear thickness of the $i$ th measuring ring. The wear volume of each measuring ring is different under different radial force and different width of strip. When (2) is applied to the rolling calculation, the formula is very complex. It is quite difficult to achieve target requirements for calculating precisely the wear thickness of each measuring ring, which is simplified as follows:

$$
\begin{aligned}
& V_{i}(x) \\
& = \begin{cases}26 \pi\left(626 h_{i}(x)-h_{i}(x)^{2}\right) & i=1,2, \ldots, 12,27,28, \ldots, 38 \\
52 \pi\left(626 h_{i}(x)-h_{i}(x)^{2}\right) & i=13,14, \ldots, 26 .\end{cases}
\end{aligned}
$$

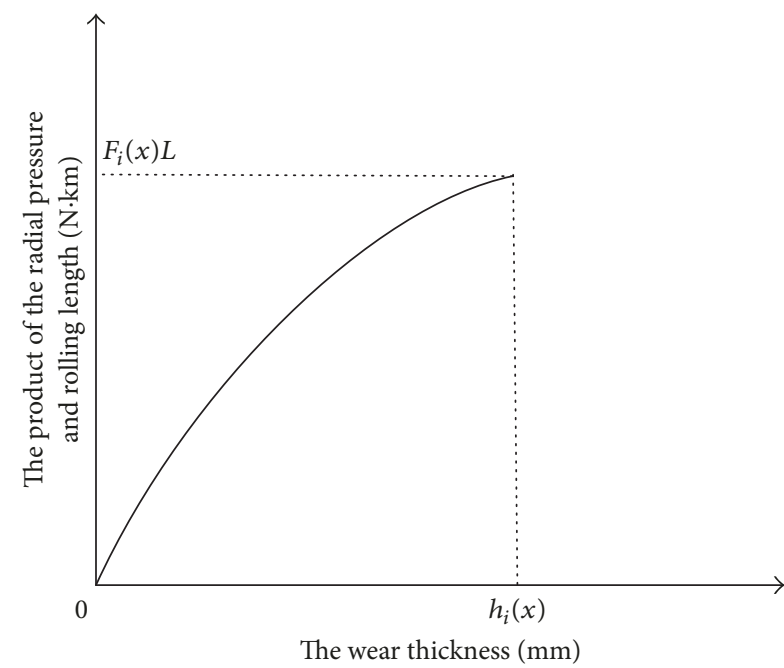

FIgURE 4: The basic relationship between $F_{i}(x) L$ and $h_{i}(x)$.

From (3), the wear thickness $h_{i}(x)$ of the $i$ th measuring ring is expressed as

$$
\begin{aligned}
& h_{i}(x) \\
& = \begin{cases}313-\sqrt{313^{2}-\frac{V_{i}(x)}{26 \pi}} & i=1,2, \ldots, 12,27,28, \ldots, 38 \\
313-\sqrt{313^{2}-\frac{V_{i}(x)}{52 \pi}} & i=13,14, \ldots, 26 .\end{cases}
\end{aligned}
$$

Substituting (1) into (4), the formula is expressed as

$$
\begin{aligned}
& h_{i}(x) \\
& = \begin{cases}313-\sqrt{313^{2}-\frac{K_{\mathrm{abr}} F_{i}(x) L}{26 \pi H}} & i=1,2, \ldots, 12,27,28, \ldots, 38 \\
313-\sqrt{313^{2}-\frac{K_{\mathrm{abr}} F_{i}(x) L}{52 \pi H}} & i=13,14, \ldots, 26,\end{cases}
\end{aligned}
$$

where $K_{\mathrm{abr}}$ is the average value of wear coefficient of measuring rings $\left(6.02 \times 10^{-7} \mathrm{~mm}^{3} \cdot \mathrm{kN}^{-1} \mathrm{~m}^{-1}\right)$.

During the strip rolling process, it is assumed that the radial force $F_{i}(x)$ is a constant along the transverse direction of the strip; when $F_{i}(x) L$, the product of the radial pressure $F_{i}(x)$ and rolling length $L$, is gradually increasing with the increase of rolling length $L$, the wear thickness $h_{i}(x)$ of the $i$ th measuring ring is also gradually increasing in (5). The basic relationships between the product $F_{i}(x) L$ and wear thickness $h_{i}(x)$ of the $i$ th measuring ring are shown in Figure 4.

It is convenient in the theory that the wear thickness $h_{i}(x)$ is determined by the product of radial force $F_{i}(x)$ and rolling length $L$. However, in the cold strip rolling process, the control accuracy is affected by complex detection principle of flatness measuring roll. Moreover, online precision of flatness measuring roll is difficult to be achieved in the wear compensation model. Firstly, the rolling length of strip needs to be calculated accurately, the program must be modified, and approximately 6 million tons of strip steel rolling length needs to be accumulated accurately by the product of rolling 
velocity and rolling time of each coil strip for a long time. Secondly, the radial force is also changed dynamically acting on the flatness measuring roll because there is a nonparallel roll gap across the width of the strip. The different radial force has different effects on wear volume of each measuring ring, and the radial forces need to be handled accurately. Thirdly, the number of measuring rings used is different in the rolling process because there are various widths for strip.

In the above conditions, the high flatness measurement accuracy can be achieved with difficulty by the flatness measuring roll, and there is a deviation between the flatness target values and flatness actual values. Besides, the tandem mill is a continuous rolling mill, and a certain amount of grade strip must be stored in loop for meeting continuous rolling. In general, a certain amount of single grade strip is rolled to achieve efficient production for the rolling schedule. The same raw materials have the similar surface quality and the similar shape crown. Beyond that, the surface quality of strip is divided into smooth surface and rough surface. A ratio factor $\xi$ is given to adjust surface quality of strip for customer's request. Generally speaking, (6) is suitable for rolling the surface smooth strip (smooth surface: $\xi=1.0$ ); when the steel strip with the rough surface has been rolled, the wear volume of measuring ring of flatness measuring roll is 1.1016 times larger than that of the steel strip with smooth surface in the same amount of rolling length (rough surface: $\xi=1.1016)$. The range of radial force is divided into several intervals and the Minitab software is used to calculate the weight of the radial force in each interval. When the strip is rolled continuously, the wear volume of the $i$ th measuring ring is calculated as follows:

$$
\begin{aligned}
V_{i}(x)= & \frac{\xi K_{\mathrm{abr}} L}{H} \cdot \sum_{i=1}^{n} \bar{F}_{i}(x) \\
= & \frac{\xi K_{\mathrm{abr}} L}{H} \\
& \cdot\left(\frac{k_{i 1}}{k} \widehat{F}_{1}(x)+\frac{k_{i 2}}{k} \widehat{F}_{2}(x)+\cdots+\frac{k_{i n}}{k} \widehat{F}_{n}(x)\right) \\
= & \frac{\xi K_{\mathrm{abr}} L}{H k} \cdot\left[\begin{array}{llll}
k_{i 1} & k_{i 2} & \cdots & k_{i 10}
\end{array}\right]_{1 \times n} \cdot\left[\begin{array}{c}
\widehat{F}_{1} \\
\widehat{F}_{2} \\
\vdots \\
\widehat{F}_{n}
\end{array}\right]_{n \times 1}, \\
L= & \sum v t,
\end{aligned}
$$

where $k$ is the collecting times of the $i$ th measuring rings with $52 \mathrm{~mm}$ wide measuring zone; $k_{i j} / k$ is the weight coefficient; $L$ is the total rolling length of strip $(\mathrm{km}) ; v$ is the rolling speed of each coil strip $(\mathrm{km} / \mathrm{h})$; and $t$ is the rolling time of each coil strip (h). Substituting (6) and (7) into (5), the formula is expressed as

$$
\begin{aligned}
& h_{i}(x) \\
& = \begin{cases}313-\sqrt{313^{2}-\frac{\left(\left(\xi K_{\mathrm{abr}} \cdot \sum v t\right) / H\right) \cdot\left(\left(k_{i 1} / k\right) \widehat{F}_{1}(x)+\left(k_{i 2} / k\right) \widehat{F}_{2}(x)+\cdots+\left(k_{i 10} / k\right) \widehat{F}_{10}(x)\right)}{26 \pi}} & i=1,2, \ldots, 12,27,28, \ldots, 38 \\
313-\sqrt{313^{2}-\frac{\left(\left(\xi K_{\mathrm{abr}} \cdot \sum v t\right) / H\right) \cdot\left(\left(k_{i 1} / k\right) \widehat{F}_{1}(x)+\left(k_{i 2} / k\right) \widehat{F}_{2}(x)+\cdots+\left(k_{i 10} / k\right) \widehat{F}_{10}(x)\right)}{52 \pi}} & i=13,14, \ldots, 26 .\end{cases}
\end{aligned}
$$

During the strip rolling process, the wear thickness of measuring rings is the main reason for decreasing measuring precision of the flatness measuring roll and it affects the measurement accuracy of the radial force. The measured values of radial force will be changed more or less when the measuring rings of flatness measuring roll are worn, and the flatness deviation between flatness measured values and the flatness actual values will be increased in a certain range.

The outermost layer strip length $l_{i}(x)$ between the deflector roll and the coiler is a variable with the increase of coil radius and the wear thickness of measuring rings. The wear volume of each measuring ring is different under different load conditions and different strip width, and the outermost layer strip length $l_{i}(x)$ is also different in Figure 5.

After the flatness measuring roll being worn, the geometric relationships are expressed as

$$
\alpha=\tan ^{-1} \frac{e_{0}}{a_{2}},
$$

$$
\begin{aligned}
& \beta=\cos ^{-1} \frac{\left(R_{1}-\bar{h}_{i}(x)+R_{2}+n h_{1}\right) \sin \alpha}{e_{0}}, \\
& \gamma=\frac{\pi}{2}-(\beta-\alpha), \\
& \delta=\tan ^{-1} \frac{e_{2}}{a_{1}} \\
& \theta=\gamma-\delta .
\end{aligned}
$$

Substituting (9), (10), (11), and (12) into (13), the formula is as follows:

$$
\begin{aligned}
\theta & =\frac{\pi}{2} \\
& -\left(\cos ^{-1} \frac{\left(R_{1}-\bar{h}_{i}(x)+R_{2}+n h_{1}\right) \sin \left(\tan ^{-1}\left(e_{0} / a_{2}\right)\right)}{e_{0}}\right. \\
& \left.-\tan ^{-1} \frac{e_{0}}{a_{2}}\right)-\tan ^{-1} \frac{e_{2}}{a_{1}}
\end{aligned}
$$




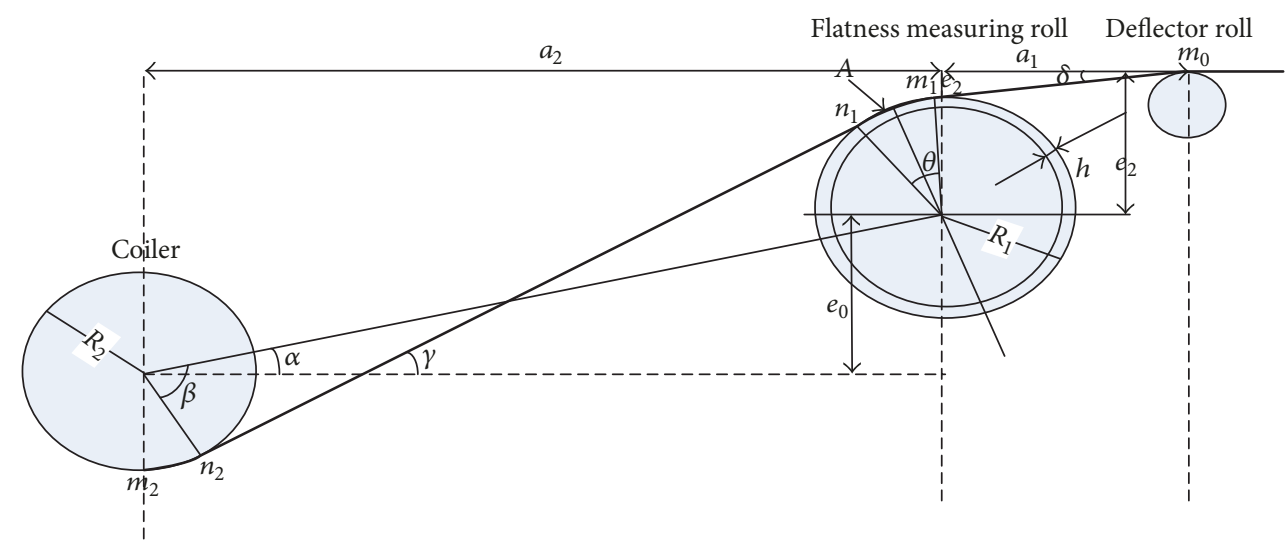

FIGURE 5: Transverse profile of the $i$ th measuring rings of flatness measuring roll.

where $e_{0}$ is the center distance between the flatness measuring roll and the coiler in the vertical direction $(\mathrm{mm}), e_{2}$ is the center distance between the flatness measuring roll and the deflector roll in the vertical direction ( $\mathrm{mm}), a_{1}$ is the distance between the center of flatness measuring roll and the upper surface of deflector roll in the horizontal direction $(\mathrm{mm}), a_{2}$ is the center distance between flatness measuring roll and coiler in the horizontal direction (mm), $n$ is the number of strip coiled layers for coiling machine, $h_{1}$ is the exit strip thickness $(\mathrm{mm}), \bar{h}_{i}(x)$ is average wear thickness of the measuring ring $(\mathrm{mm}), R_{1}$ is the radius before flatness measuring roll worn $(\mathrm{mm})$, and $R_{2}$ is the axis radius of coiler with drum $(\mathrm{mm})$.

Based on the geometrical relationship between the deflector roll and the coiler in Figure 5, when $n$ layers strip is coiled, for the $i$ th measuring ring, the outermost layer strip length $l_{i}(x)$ between the deflector roll and the coiler can be obtained along the longitudinal direction of the strip:

$$
\begin{aligned}
l_{i}(x)= & m_{0} m_{1}+m_{1} n_{1}+n_{1} n_{2}+n_{2} m_{2} \\
= & (\theta+\tan \beta)\left(R_{1}-h_{i}(x)\right)+\left(R_{2}+n h_{1}\right) \tan \beta \\
& +\frac{a_{1}}{\cos \delta}+\left(R_{1}-h_{i}(x)\right) \tan \delta \\
& +2 \pi\left(R_{2}+n h_{1}\right),
\end{aligned}
$$

where $\theta$ is the wrap angle between strip and flatness measuring roll (rad). When the distance between the deflector roll and coiler is reduced by the wear of measuring rings along the longitudinal direction of the strip, the radial force actual values are less than the radial force measured values. According to the rolling deformation theory, the flatness deviation caused by wear of the $i$ th measuring ring of the flatness measuring roll is as follows:

$$
\sigma_{\text {wear }, i}(x)=\frac{E}{1-v^{2}}\left(\frac{l_{i}(x)-\sum_{i=1}^{m} l_{i}(x) / m}{\sum_{i=1}^{m} l_{i}(x) / m}\right),
$$

where $m$ is the number of measuring rings, $v$ is the Poisson coefficient of strip, and $E$ is the elasticity coefficient of strip.
The target values of flatness curve should be ideally accordant with online flatness measured values if the actual radial force distribution can keep up to the range of radial force in the normal tension. However, the measuring rings have been worn down in the driving process of friction between flatness measuring roll and strip, and the flatness deviation increases because of the wear of the measuring rings. Hence, it is necessary to add the wear compensation model to flatness target curve for improving measurement accuracy of flatness measuring roll and the strip quality. The flatness target curve is composed of the basic target curve and all kinds of compensation curves:

$$
\begin{aligned}
\Delta \sigma_{i}(x)= & \sigma_{\mathrm{base}, i}(x)+\sigma_{\mathrm{cs}, i}(x)+\sigma_{\mathrm{geo}, i}(x)+\sigma_{\mathrm{tilt}, i}(x) \\
& +\sigma_{\mathrm{edge}, i}(x)+\sigma_{\mathrm{bend}, i}(x)+\sigma_{\mathrm{temp}, i}(x)+-\bar{\sigma} \\
= & a_{1} x^{4}+a_{2} x^{3}+a_{3} x^{2}+a_{4} x+a_{5} .
\end{aligned}
$$

The average flatness values is calculated by

$$
\begin{gathered}
\bar{\sigma}_{i}(x)=\frac{1}{n} \sum_{i=1}^{n}\left(\sigma_{\mathrm{cs}, i}(x)+\sigma_{\mathrm{geo}, i}(x)+\sigma_{\mathrm{tilt}, i}(x)\right. \\
\left.+\sigma_{\text {edge }, i}(x)+\sigma_{\mathrm{bend}, i}(x)+\sigma_{\mathrm{temp}, i}(x)\right),
\end{gathered}
$$

where $\sigma_{\mathrm{base}, i}(x)$ is the basic setting curve, $\sigma_{\mathrm{cs}, i}(x)$ is the crimp shape compensation curve, $\sigma_{\text {geo }, i}(x)$ is the erection geometric error compensation curve of the coiler, $\sigma_{\text {tilt, } i}(x)$ is the roll lean compensation curve, $\sigma_{\text {bend, } i}(x)$ is the roll deflection compensation curve, $\sigma_{\text {edge, } i}(x)$ is the strip edge thinning compensation curve, and $\sigma_{\text {temp,i }}(x)$ is the strip transverse temperature compensation curve. $a_{1}$ and $a_{2}$ are the proportional coefficients of composite wave without wear compensation model; $a_{3}$ and $a_{4}$ are the proportional coefficients of bilateral wave and unilateral wave without wear compensation model, respectively; $a_{5}$ is constant term without wear compensation 
model. When the wear compensation model is established, the flatness target curve is described as follows:

$$
\begin{aligned}
\Delta \sigma_{i}^{\prime}(x)= & \sigma_{\mathrm{base}, i}(x)+\sigma_{\mathrm{cs}, i}(x)+\sigma_{\mathrm{geo}, i}(x)+\sigma_{\mathrm{tilt}, i}(x) \\
& +\sigma_{\mathrm{edge}, i}(x)+\sigma_{\mathrm{bend}, i}(x)+\sigma_{\mathrm{temp}, i}(x) \\
& +\sigma_{\mathrm{wear}, i}(x)-\bar{\sigma} \\
= & a_{1}^{\prime} x^{4}+a_{2}^{\prime} x^{3}+a_{3}^{\prime} x^{2}+a_{4}^{\prime} x+a_{5}^{\prime} .
\end{aligned}
$$

Average flatness values are calculated as follows:

$$
\begin{aligned}
& \bar{\sigma}_{i}^{\prime}(x)=\frac{1}{n} \sum_{i=1}^{n}\left(\sigma_{\mathrm{cs}, i}(x)+\sigma_{\mathrm{geo}, i}(x)+\sigma_{\mathrm{tilt}, i}(x)\right. \\
& \left.+\sigma_{\mathrm{edge}, i}(x)+\sigma_{\mathrm{bend}, i}(x)+\sigma_{\mathrm{temp}, i}(x)+\sigma_{\mathrm{wear}, i}(x)\right),
\end{aligned}
$$

where $\sigma_{\text {wear }, i}(x)$ is the wear compensation curve of the measuring rings of flatness measuring roll; $a_{1}^{\prime}$ and $a_{2}^{\prime}$ are the proportional coefficients of composite wave with wear compensation model; $a_{3}^{\prime}$ and $a_{4}^{\prime}$ are the proportional coefficients of bilateral wave and unilateral wave with wear compensation model, respectively; $a_{5}^{\prime}$ is constant term with wear compensation model.

\section{Results}

Taking the data of the six million tons' strip as an experiment, the measuring rings volume removed $\sum_{i=1}^{38} V_{i}(x)$ of flatness measuring roll is researched by definite integral method, theory of Archard, and weighted coefficient method. The wrap angle $\theta$ is calculated in (14) and the wear volume $V_{i}(x)$ is calculated by the weighted coefficient method in (6). The wear thickness of measuring rings $h_{i}(x)$ is calculated by (8), and the flatness deviation of wear compensation model $\Delta \sigma_{i}^{\prime}(x)$ is calculated by (16), and the final flatness deviation is calculated by (19).

$F_{i}(x)$ is the radial force of the $i$ th measuring ring along the longitudinal direction of the strip, and it is from Siemens TDC (Technology and Drives Control) controller of flatness related continuous function block, which is online measured value with dynamic wrap angle. The process of handling a large amount of data is very tedious, and some flatness measurement outliers need to be processed for improving the authenticity of the data. The total strip rolling length is calculated by summation of each coil strip product of rolling time and rolling velocity. 330 sets of flatness data are collected for each coil strip along the longitudinal direction of the strip and the numbers of strip coils are about 300,000 volumes.

There are 24 measuring rings with the $26 \mathrm{~mm}$ wide measuring zone, and the radial force of each measuring ring is the range of $3.5 \mathrm{kN}$ to $5.0 \mathrm{kN}$, there are 14 measuring rings with the $52 \mathrm{~mm}$ wide measuring zone, and the radial force of each measuring ring is the range of $7.0 \mathrm{kN}$ to $10.0 \mathrm{kN}$. It is convenient for calculation that the radial force of a half measuring ring with $52 \mathrm{~mm}$ wide measuring zone is the range of $3.5 \mathrm{kN}$ to $5.0 \mathrm{kN}$. When the measuring rings are worn gradually, the small change of wrap angle between the strip and flatness measuring roll is ignored. The range of radial force is divided into 10 intervals, and the radial force collecting times of each measuring ring are more than ten million times. The Minitab software is used to calculate the weight of the radial force in each interval, and it is also important to discard the abnormal flatness measured values. The number of acquisitions of different radial force range of measuring rings is shown in Table 1.

Table 1 indicates that the radial force is collected in different radial force intervals of each measuring ring and the collected times of each measuring ring are described in detail as follows. The sums of data acquisition times of each measuring ring are different because some grade strip does not always cover the all measuring rings at the edge of the flatness measuring roll. When the measuring rings are not covered by the strip, the collection time is zero. For example, the acquisition times of the 3 rd measuring ring are $4.61 \times 10^{7}$; the acquisition times of the 5 th measuring ring are $4.61 \times 10^{7}$; however, the acquisition times of the 7 th measuring ring are $6.9 \times 10^{7}$; the acquisition times of the 10th measuring ring are $1.0 \times 10^{8}$. The weight coefficients of each measurement ring are also different.

The radial force data of six million tons' strip are used to demonstrate the accuracy of the wear compensation model. It is necessary to consider the weight of the radial force in the range of each measuring ring and the width of the strip in the process of data statistics. The production and rolling length of different grades strip are described in Table 2. From Table 2, the length and width of different grade strip are one of the main factors to determine the wear thickness of each measuring ring. The number of measuring rings used is determined by the width of strip.

Table 2 indicates that the production, rolling length, and width of strip are collected in different grade strips. When the strip head and the strip tail are cut down, the average coil weight of strip is about 20 tons, the raw material thickness is between $2.0 \mathrm{~mm}$ and $3.5 \mathrm{~mm}$, the exit strip thickness is between $0.20 \mathrm{~mm}$ and $1.8 \mathrm{~mm}$, and the strip width is between $850 \mathrm{~mm}$ and $1300 \mathrm{~mm}$, respectively. The average strip crown is $7 \mu \mathrm{m}$, and thirty-eight measuring rings of flatness measuring roll are used to measure strip flatness. The length of total rolled strip is about $1920156 \mathrm{~km}$. The millions of radial force data are collected from the database to obtain weighted coefficient of radial force.

The numbers of measuring rings used are determined by the width of rolled strip. If less than half of the area of one measuring ring is not covered, the radial force of the measuring ring will be ignored and there is no wear volume on the surface of measuring rings. For example, when the width of strip exceeds $1150 \mathrm{~mm}$, at least 30 measuring rings are used to measure the flatness of the strip; when the width of strip is between $1000 \mathrm{~mm}$ and $1150 \mathrm{~mm}$, about 24 and 30 measuring rings are used to measure the flatness of the strip, and when the width of strip is between $850 \mathrm{~mm}$ and $1000 \mathrm{~mm}$, about 18 and 24 measuring rings are used to measure the flatness of the strip.

Because the proportion of rough surface of strip is very small and can be ignored in Table $2, \xi=1.0$ is used 


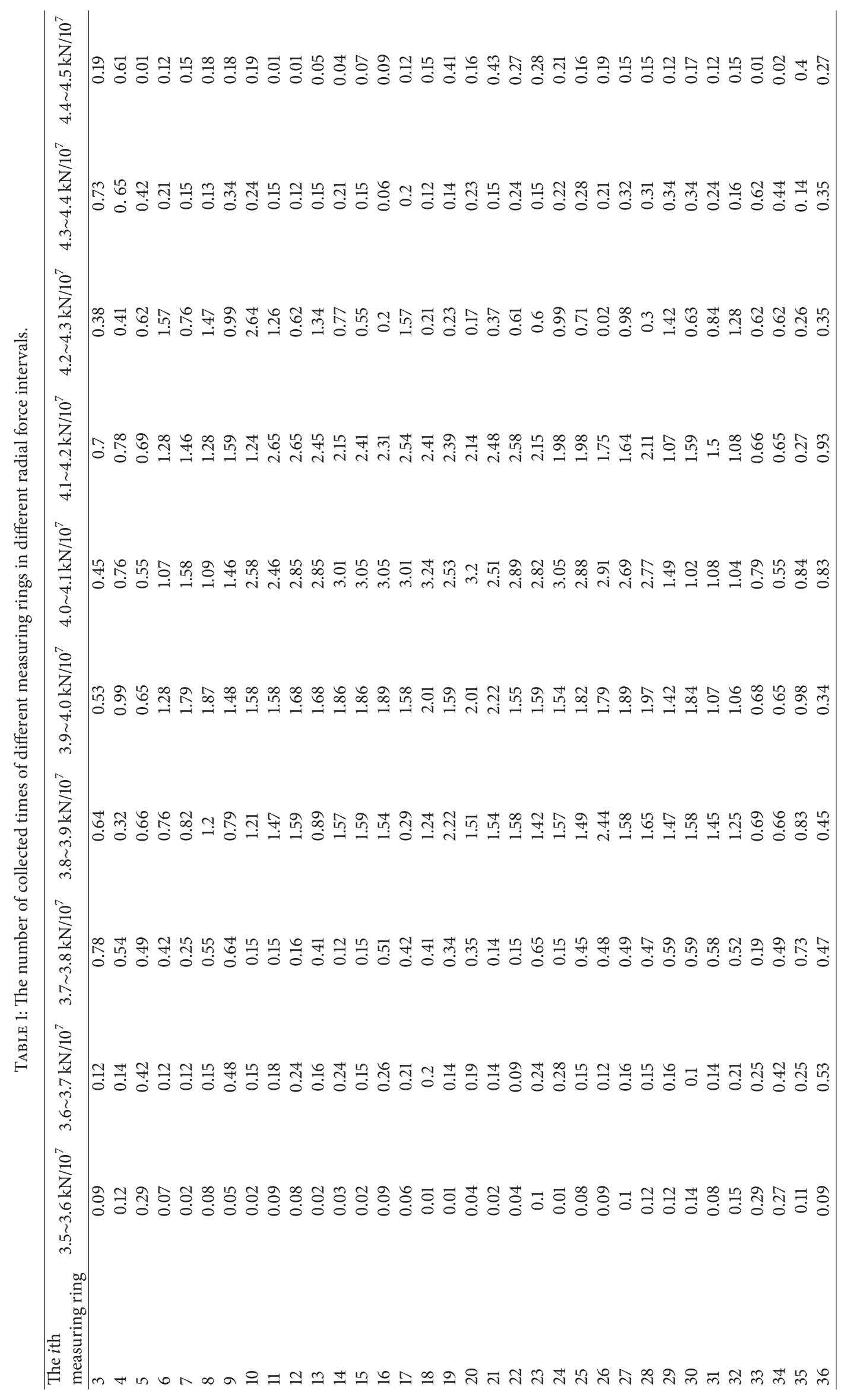


TABLE 2: The production and rolling length of different grade strip.

\begin{tabular}{|c|c|c|c|c|}
\hline The width of strip & Q195 grade strip & SPHC grade strip & SPHD grade strip & Others \\
\hline Total production/t & 1256640.4 & 833280.6 & 138881.6 & 11201.6 \\
\hline$\geqslant 1150 \mathrm{~mm}$ production $/ \mathrm{t}$ & 462424.4 & 485820.2 & 83312.8 & 3921.0 \\
\hline $1000 \sim 1150 \mathrm{~mm}$ production/t & 555413.5 & 322467.9 & 55525.2 & 4484.0 \\
\hline$\leqslant 1000 \mathrm{~mm}$ production/t & 213622.9 & 12492.9 & 14534.9 & 2810.0 \\
\hline Total length $/ \mathrm{km}$ & 974148.1 & 798911.8 & 144557.8 & 2537.8 \\
\hline$\geqslant 1150 \mathrm{~mm}$ rolling length $/ \mathrm{km}$ & 325261.6 & 428205.2 & 84336.3 & 1326.3 \\
\hline $1000 \sim 1150 \mathrm{~mm}$ rolling length $/ \mathrm{km}$ & 462564.4 & 360283.5 & 60221.5 & 1211.5 \\
\hline $850 \sim 1000 \mathrm{~mm}$ rolling length $/ \mathrm{km}$ & 186322.1 & 10423.1 & 0.0 & 0.0 \\
\hline Strip with rough surface/\% & 1.7 & 2.6 & 0.0 & 0.0 \\
\hline Strip with smooth surface/\% & 98.3 & 97.4 & 0.0 & 0.0 \\
\hline Yield/MPa & $\geq 195$ & $\leqslant 260$ & $\leqslant 240$ & -- \\
\hline Ultimate stresses/MPa & $315 \sim 420$ & $\geq 270$ & $\geq 270$ & -- \\
\hline
\end{tabular}

for calculation. The wear volume of each measuring ring is calculated as follows by (6):

$$
\begin{aligned}
& {\left[\begin{array}{c}
V_{3}(x) \\
V_{4}(x) \\
\vdots \\
V_{36}(x)
\end{array}\right]} \\
& =\frac{\xi K_{\mathrm{abr}} L}{H k} \cdot\left[\begin{array}{cccc}
k_{11} & k_{12} & \cdots & k_{110} \\
k_{21} & k_{22} & \cdots & k_{210} \\
\vdots & \vdots & \ddots & \vdots \\
k_{341} & k_{342} & \cdots & k_{3410}
\end{array}\right]_{34 \times 10} \\
& \\
& {\left[\begin{array}{c}
\widehat{F}_{1} \\
\widehat{F}_{2} \\
\vdots \\
\widehat{F}_{10}
\end{array}\right]_{10 \times 1}}
\end{aligned}
$$

$$
=\frac{1.0 \times 6.02 \times 10^{-7} \times\left(1920156 \times 10^{3}\right)}{1.049 \times 1.0 \times 10^{8}}
$$$$
\left[\begin{array}{cccc}
0.09 \times 10^{7} & 0.12 \times 10^{7} & \cdots & 0.19 \times 10^{7} \\
0.12 \times 10^{7} & 0.14 \times 10^{7} & \cdots & 0.61 \times 10^{7} \\
\vdots & \vdots & \ddots & \vdots \\
0.09 \times 10^{7} & 0.13 \times 10^{7} & \cdots & 0.27 \times 10^{7}
\end{array}\right]_{34 \times 10}
$$$$
\left[\begin{array}{c}
3.55 \\
3.65 \\
\vdots \\
4.45
\end{array}\right]_{10 \times 1}=\left[\begin{array}{c}
1983 \\
2283 \\
\vdots \\
2157
\end{array}\right]_{34 \times 1}
$$

Substituting (21) into (8), the formula is expressed as

$$
\left[\begin{array}{c}
h_{3}(x) \\
\vdots \\
h_{13}(x) \\
h_{14}(x) \\
\vdots \\
h_{28}(x) \\
h_{29}(x) \\
\vdots \\
h_{36}(x)
\end{array}\right]=\left[\begin{array}{c}
313-\sqrt{313^{2}-\frac{\left(K_{\mathrm{abr}} L / H\right) \cdot\left(\left(k_{11} / k\right) \widehat{F}_{1}(x)+\left(k_{12} / k\right) \widehat{F}_{2}(x)+\cdots+\left(k_{110} / k\right) \widehat{F}_{10}(x)\right)}{26 \pi}} \\
313-\sqrt{313^{2}-\frac{\left(\xi K_{\mathrm{abr}} L / H\right) \cdot\left(\left(k_{111} / k\right) \widehat{F}_{1}(x)+\left(k_{112} / k\right) \widehat{F}_{2}(x)+\cdots+\left(k_{1110} / k\right) \widehat{F}_{10}(x)\right)}{26 \pi}} \\
313-\sqrt{313^{2}-\frac{\left(\xi K_{\mathrm{abr}} L / H\right) \cdot\left(\left(k_{121} / k\right) \widehat{F}_{1}(x)+\left(k_{122} / k\right) \widehat{F}_{2}(x)+\cdots+\left(k_{1210} / k\right) \widehat{F}_{10}(x)\right)}{52 \pi}} \\
313-\sqrt{313^{2}-\frac{\left(\xi K_{\mathrm{abr}} L / H\right) \cdot\left(\left(k_{261} / k\right) \widehat{F}_{1}(x)+\left(k_{262} / k\right) \widehat{F}_{2}(x)+\cdots+\left(k_{2610} / k\right) \widehat{F}_{10}(x)\right)}{52 \pi}} \\
313-\sqrt{313^{2}-\frac{\left(\xi K_{\mathrm{abr}} L / H\right) \cdot\left(\left(k_{271} / k\right) \widehat{F}_{1}(x)+\left(k_{272} / k\right) \widehat{F}_{2}(x)+\cdots+\left(k_{2710} / k\right) \widehat{F}_{10}(x)\right)}{26 \pi}} \\
313-\sqrt{313^{2}-\frac{\left(\xi K_{\mathrm{abr}} L / H\right) \cdot\left(\left(k_{341} / k\right) \widehat{F}_{1}(x)+\left(k_{342} / k\right) \widehat{F}_{2}(x)+\cdots+\left(k_{3410} / k\right) \widehat{F}_{10}(x)\right)}{26 \pi}}
\end{array},\right.
$$


TABLE 3: The wear thickness of the measured values and the predicted values.

\begin{tabular}{|c|c|c|c|c|c|c|c|c|c|c|c|c|c|}
\hline The ith measuring ring & 1 & 2 & 3 & 4 & 5 & 6 & 7 & 8 & 9 & 10 & 11 & 12 & 13 \\
\hline $\begin{array}{l}\text { The wear volume of the } i \text { th } \\
\text { measuring ring } / \mathrm{mm}^{3}\end{array}$ & 0.00 & 0.00 & 1983 & 2233 & 2187 & 3269 & 3372 & 3374 & 3670 & 4662 & 4669 & 4662 & 9336 \\
\hline Predicted values/mm & 0.00 & 0.00 & 0.039 & 0.044 & 0.042 & 0.064 & 0.065 & 0.073 & 0.072 & 0.091 & 0.091 & 0.091 & 0.092 \\
\hline Measured values/mm & 0.00 & 0.00 & 0.043 & 0.043 & 0.045 & 0.064 & 0.067 & 0.073 & 0.077 & 0.094 & 0.093 & 0.092 & 0.092 \\
\hline The $i$ th measuring ring & 14 & 15 & 16 & 17 & 18 & 19 & 20 & 21 & 22 & 23 & 24 & 25 & 26 \\
\hline $\begin{array}{l}\text { The wear volume of the } i \text { th } \\
\text { measuring ring } / \mathrm{mm}^{3}\end{array}$ & 9247 & 9305 & 9330 & 9349 & 9316 & 9297 & 9200 & 9326 & 9259 & 9283 & 9262 & 9173 & 9161 \\
\hline Predicted values $/ \mathrm{mm}$ & 0.090 & 0.091 & 0.091 & 0.091 & 0.091 & 0.091 & 0.090 & 0.091 & 0.090 & 0.090 & 0.090 & 0.09 & 0.09 \\
\hline Measured values $/ \mathrm{mm}$ & 0.090 & 0.093 & 0.094 & 0.093 & 0.094 & 0.094 & 0.094 & 0.093 & 0.093 & 0.092 & 0.093 & 0.093 & 0.092 \\
\hline The ith measuring ring & 27 & 28 & 29 & 30 & 31 & 32 & 33 & 34 & 35 & 36 & 37 & 38 & --- \\
\hline $\begin{array}{l}\text { The wear volume of the } i \text { th } \\
\text { measuring ring } / \mathrm{mm}^{3}\end{array}$ & 4565 & 4557 & 3758 & 3654 & 3311 & 3264 & 2114 & 2166 & 2323 & 2157 & 0.00 & 0.00 & --- \\
\hline Predicted values $/ \mathrm{mm}$ & 0.09 & 0.09 & 0.089 & 0.071 & 0.065 & 0.064 & 0.042 & 0.042 & 0.043 & 0.042 & 0.00 & 0.00 & --- \\
\hline Measured values/mm & 0.093 & 0.090 & 0.088 & 0.071 & 0.067 & 0.060 & 0.046 & 0.042 & 0.043 & 0.044 & 0.00 & 0.00 & --- \\
\hline
\end{tabular}

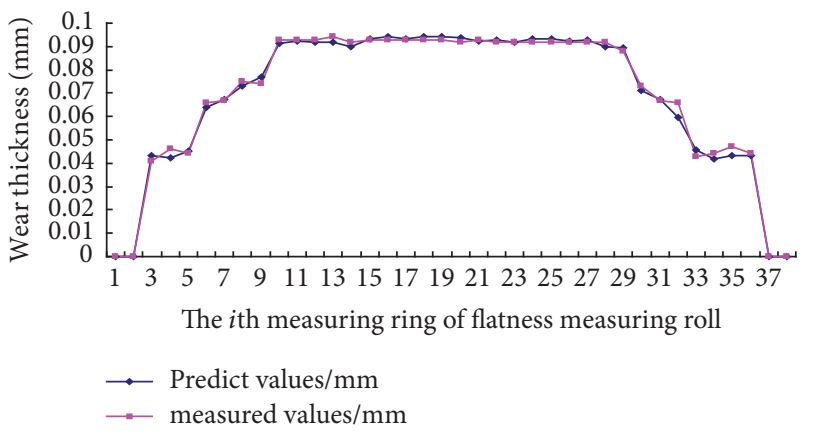

Figure 6: The wear thickness of flatness measuring roll along the axial directing.

where $\widehat{F}_{i}(x)$ is intermediate radial force of the $i$ th intervals (median, $\mathrm{kN}$ ). The wear thickness predicted values of the $i$ th measuring ring are calculated by (22), as shown in Table 3.

During the cold strip rolling process, the total tension of flatness measuring roll should be considered to be reliable and stable. The measured values and calculated values of wear thickness are shown in Table 3 and Figure 6. The average wear thickness deviation between actual measured values and the predicted values is $0.004 \mathrm{~mm}$ and can be ignored. The closer the edge measuring rings of the flatness measuring roll are, the smaller the wear volume of the measuring rings is.

In Figure 6 and Table 3, when the rolling length is $1920156 \mathrm{~km}$, there are 4 measuring rings in terms of the 1st measuring ring, the 2 nd measuring ring, 37th measuring ring, and 38th measuring ring, they have little contact with strip, and hence the wear volumes of these measuring rings are close to zero. Moreover, the longer the rolled strip is, the bigger the wear volume will be for the 3rd measuring ring to 36 th measuring ring. Additionally, the central section of flatness measuring roll has more wear volume than that of its edge. The maximum wear volume of measuring ring is
$9326 \mathrm{~mm}^{3}$ and the maximum wear thickness of measuring ring is $0.092 \mathrm{~mm}$. From Figure 6, the different width of strip is the main reason why there is a different wear volume in each of the measuring rings. The width of the rolling strip is different, and the radial force acquisition times of each measuring ring are different. The radial force deviation has little influence on the wear of flatness measuring roll from 10 th measuring ring to 28 th measuring ring. These measuring rings of flatness measuring roll have no uniform wear thickness and it affects the flatness measurement accuracy. The wear volume of measuring ring is changed with the width and rolling length of strip.

Based on the above analysis of the wear of flatness measuring roll under the radial pressure, the wear thickness of the measuring rings has effects on the flatness measurement accuracy. The compensation model should be established for the wear of flatness measuring roll. Hence, the flatness deviation between predicted values and measured values should be erased by adding wear compensation model to the flatness target curve. Depending on the analysis, the wear compensation model $\sigma_{\text {wear }, i}(x)$ caused by wear thickness $h_{i}(x)$ is obtained by (16) and final flatness deviation $\Delta \sigma_{i}^{\prime}(x)$ is obtained by (19). In order to prove the validity of the wear compensation model, the grades of SPCC, Q195, and SPCD are used for rolling experiments. The related equipment parameters and flatness measuring roll parameters are shown in Table 4.

The wear compensation model of flatness measuring roll has been carried out in the $1450 \mathrm{~mm}$ cold rolling mill. The grades of strip are SPCC, Q195, and SPCD, respectively. The rolling parameters are shown in Table 5. The deviation between flatness target values and measured values is shown in Figure 7.

According to the measured values of flatness measuring system of the Sheet Inc. of Iron and Steel Co., the experiment is done by the $1450 \mathrm{~mm}$ cold rolling mill. Industrial application effect of the wear compensation model of shape detecting 
TABLE 4: The equipment parameters and flatness measuring roll parameters.

\begin{tabular}{|c|c|c|c|}
\hline \multicolumn{2}{|c|}{ Equipment parameters } & \multicolumn{2}{|c|}{ Flatness measuring roll parameters } \\
\hline Roll material & High chromium steel & Flatness measuring roll diameter $/ \mathrm{mm}$ & 313 \\
\hline Steel material & SPHC, SPHD, Q195 (carbon steel) & Flatness measuring roll barrel length $/ \mathrm{mm}$ & 1350 \\
\hline Work roll barrel length/mm & 1450 & Number of rings & 38 \\
\hline Work diameter $/ \mathrm{mm}$ & 400 & Width of measuring rings $/ \mathrm{mm}$ & $26 / 52$ \\
\hline Average rolling speed $/ \mathrm{m} \cdot \mathrm{s}^{-1}$ & 19.7 & Hardness of measuring rings/HRC & 58 \\
\hline
\end{tabular}

TABLE 5: The rolling parameters of different grade strip.

\begin{tabular}{|c|c|c|c|c|c|c|c|}
\hline Strip type & Rolling pass & $\begin{array}{c}\text { Entry } \\
\text { thickness/mm }\end{array}$ & $\begin{array}{c}\text { Exit } \\
\text { thickness/mm }\end{array}$ & $\begin{array}{l}\text { Reduction } \\
\text { rate } / \%\end{array}$ & $\begin{array}{c}\text { Unit } \\
\text { tension } / \mathrm{kN} \cdot \mathrm{mm}^{-1}\end{array}$ & $\begin{array}{l}\text { Rolling } \\
\text { force/kN }\end{array}$ & $\begin{array}{c}\text { Rolled } \\
\text { speed } / \mathrm{m} \cdot \mathrm{min}^{-1}\end{array}$ \\
\hline \multirow{5}{*}{ Q195 } & 1 & 2.75 & 1.804 & 34.40 & 145.87 & 8450 & 240 \\
\hline & 2 & 1.804 & 1.053 & 41.63 & 156.3 & 9430 & 440 \\
\hline & 3 & 1.053 & 0.626 & 40.55 & 150.1 & 9190 & 656 \\
\hline & 4 & 0.626 & 0.392 & 37.38 & 144.56 & 9250 & 924 \\
\hline & 5 & 0.392 & 0.26 & 33.67 & 132.45 & 8750 & 1113 \\
\hline \multirow{5}{*}{ SPCC } & 1 & 2.5 & 1.609 & 35.64 & 143.244 & 8430 & 250 \\
\hline & 2 & 1.6099 & 0.981 & 39.06 & 151.23 & 9350 & 442 \\
\hline & 3 & 0.901 & 0.561 & 37.74 & 145.61 & 9110 & 676 \\
\hline & 4 & 0.501 & 0.305 & 39.12 & 134.56 & 9150 & 934 \\
\hline & 5 & 0.305 & 0.261 & 14.43 & 122.55 & 8350 & 1120 \\
\hline \multirow{5}{*}{ SPCD } & 1 & 2.5 & 1.482 & 40.72 & 135.47 & 8550 & 250 \\
\hline & 2 & 1.482 & 0.865 & 41.63 & 1461.3 & 9230 & 4530 \\
\hline & 3 & 0.865 & 0.534 & 38.27 & 144.41 & 9110 & 675 \\
\hline & 4 & 0.534 & 0.325 & 39.14 & 114.56 & 9200 & 934 \\
\hline & 5 & 0.325 & 0.24 & 26.15 & 112.45 & 8250 & 1010 \\
\hline
\end{tabular}

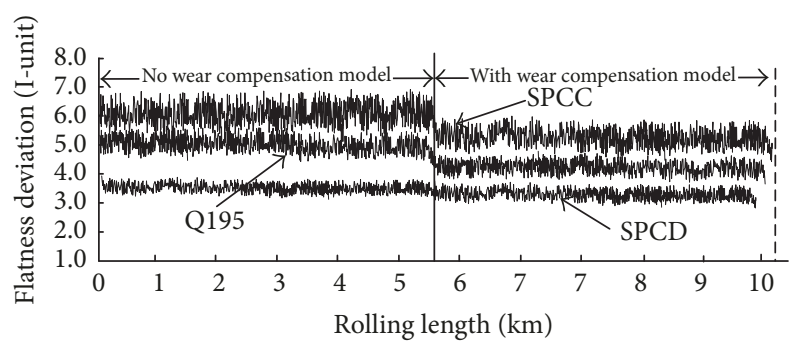

Figure 7: Calculation of compensation quantity caused by wear of shape detecting roll.

roll was shown in Figure 7. The average plate crown of strip is $7 \mu \mathrm{m}$ and can be neglected.

The flatness deviation of shape detecting roll is reliable and stable in Figure 7, and there is no significant fluctuation after adding the compensation curve of the shape detecting roll to the flatness target curve.

It is assumed that wear thickness in (22) is zero. In other words, the wear thickness of the shape detecting roll is ignored. When the wear compensation model is not done for the flatness control system, there is a larger deviation between flatness target values and measured values, as shown in Figure 5, the average strip flatness of SPCC, Q195, and SPCD is 6.5 I-units, $5.2 \mathrm{I}$-units, and $3.8 \mathrm{I}$-units, respectively, when the wear compensation model is added to the flatness target curve, it can be seen that there is a smaller deviation between flatness target values and measuring values, and the average strip flatness of SPCC, Q195, and SPCD is 5.7 Iunits, 4.6 I-units, and 3.7 I-units, respectively; the average flatness measurement accuracy is improved by 0.8 I-units, 0.6 I-units, and $0.1 \mathrm{I}$-units. The wider the strip, the greater the deviation between target values and measured values. It can be known that the flatness measurement accuracy with wear compensation model is superior to itself without wear compensation model. The results show that flatness measurement accuracy is improved by wear compensation model and the wear compensation model cannot be ignored.

From Table 6, the wider the strip is, the more deviation there is between target values and measured values. It can be known that the flatness control accuracy with wear compensation model is superior to itself without wear compensation model, and the results show that measuring precise and strip flatness is improved by wear compensation model and the wear compensation model cannot be ignored. Hence, it is necessary to introduce wear compensation model in flatness target curve to improve the strip quality.

When the wear compensation model is not added to the flatness target curve, the flatness deviation $\Delta \sigma_{i}(x)$ caused by wear thickness $h_{i}(x)$ of measuring rings is not obtained. The strip flatness is not very well after annealing, and there is edge 
TABLE 6: The average flatness measured values before and after compensation model of different grade strip.

\begin{tabular}{|c|c|c|c|c|c|c|c|c|c|c|c|c|c|}
\hline The $i$ th measuring ring & 1 & 2 & 3 & 4 & 5 & 6 & 7 & 8 & 9 & 10 & 11 & 12 & 13 \\
\hline SPCC flatness target/I & --- & --- & -10.4 & -10.1 & -9.9 & -9.5 & -9.2 & -9.1 & -7.5 & -4.4 & -1.1 & 5.9 & 6.9 \\
\hline SPCC after compensation/I & --- & --- & -10.1 & -8.5 & -8.3 & -8.1 & -7.9 & -7.3 & -6.6 & -5.4 & -2.1 & 3.0 & 4.6 \\
\hline SPCC before compensation/I & --- & --- & -8.9 & -7.1 & -7.7 & -7.7 & -6.4 & -1.9 & -6.4 & -5.0 & -1.9 & -0.5 & 3.6 \\
\hline Q195 flatness target/I & --- & --- & --- & --- & --- & -13.1 & -12.0 & -11.9 & -10.0 & -6.3 & -2.3 & 2.8 & 4.9 \\
\hline Q195 after compensation/I & --- & --- & --- & --- & --- & -12.1 & -11.0 & -10.9 & -9.0 & -5.3 & -1.3 & 3.8 & 5.9 \\
\hline Q195 before compensation/I & --- & --- & --- & --- & --- & -9.2 & -7.7 & -2.3 & -7.7 & -6.0 & -2.3 & -0.6 & 4.3 \\
\hline SPCD flatness target/I & --- & --- & --- & --- & --- & --- & --- & --- & -10.1 & -7.5 & -6.3 & -4.0 & -2.1 \\
\hline SPCD after compensation/I & --- & --- & --- & --- & --- & --- & --- & --- & -9.7 & -7.9 & -7.1 & -4.7 & -1.1 \\
\hline SPCD before compensation/I & --- & --- & --- & --- & --- & --- & --- & --- & -9.1 & -7.5 & -7.1 & -4.5 & 0.1 \\
\hline The $i$ th measuring ring & 14 & 15 & 16 & 17 & 18 & 19 & 20 & 21 & 22 & 23 & 24 & 25 & 26 \\
\hline SPCC flatness target/I & 8.1 & 9.1 & 10.8 & 11.2 & 12.8 & 12.9 & 12.8 & 11.7 & 10.7 & 9.9 & 9.8 & 7.8 & 5.5 \\
\hline SPCC before compensation/I & 6.1 & 7.6 & 7.9 & 9.6 & 10.1 & 10.7 & 9.3 & 9.3 & 7.0 & 6.5 & 5.1 & 2.6 & 1.1 \\
\hline SPCC after compensation/I & 5.9 & 7.4 & 7.7 & 9.2 & 9.7 & 10.1 & 8.5 & 8.0 & 6.0 & 6.0 & 4.4 & 2.4 & 0.9 \\
\hline Q195 flatness target/I & 7.1 & 8.3 & 8.8 & 10.7 & 11.0 & 11.5 & 11.5 & 11.5 & 8.5 & 7.4 & 6.4 & 3.2 & 1.1 \\
\hline Q195 before compensation/I & 8.1 & 9.3 & 9.8 & 11.7 & 12.0 & 12.5 & 12.7 & 12.5 & 9.5 & 8.4 & 7.4 & 4.2 & 2.1 \\
\hline Q195 after compensation/I & 7.1 & 8.9 & 9.2 & 11.0 & 11.6 & 12.1 & 10.2 & 9.6 & 7.2 & 7.2 & 5.3 & 2.9 & 1.1 \\
\hline SPCD flatness target/I & 1.2 & 3.2 & 4.9 & 6.2 & 8.1 & 8.3 & 7.5 & 6.9 & 5.5 & 4.7 & 2.1 & -1.2 & -3.5 \\
\hline SPCD before compensation/I & 1.1 & 2.5 & 4.7 & 5.0 & 6.8 & 6.3 & 5.8 & 5.5 & 3.2 & 2.4 & -0.1 & -1.2 & -3.3 \\
\hline SPCD after compensation/I & 1.3 & 3.2 & 4.6 & 4.8 & 6.6 & 5.3 & 5.2 & 5.1 & 3.2 & 2.1 & -0.9 & -1.1 & -3.1 \\
\hline The $i$ th measuring ring & 27 & 28 & 29 & 30 & 31 & 32 & 33 & 34 & 35 & 36 & 37 & 38 & average \\
\hline SPCC flatness target/I & -1.2 & -3.3 & -5.1 & -7.2 & -8.9 & -9.1 & -9.5 & -9.9 & -10.1 & -10.4 & --- & --- & 0.0 \\
\hline SPCC before compensation/I & -3.3 & -3.7 & -6.0 & -7.9 & -9.6 & -9.8 & -10.1 & -9.3 & -8.5 & -10.1 & --- & --- & 1.8 \\
\hline SPCC after compensation/I & -2.9 & -3.5 & -4.9 & -7.4 & -7.5 & -9.2 & -9.1 & -8.1 & -7.4 & -8.0 & --- & --- & 0.9 \\
\hline Q195 flatness target/I & -5.0 & -7.1 & -9.6 & -11.7 & -11.9 & -13.7 & --- & --- & --- & --- & --- & --- & 0.0 \\
\hline Q195 before compensation/I & -4.0 & -6.1 & -8.6 & -10.7 & -10.9 & -12.7 & --- & --- & --- & --- & --- & --- & 3.0 \\
\hline Q195 after compensation/I & -4.4 & -7.2 & -9.5 & -11.5 & -11.8 & -12.1 & --- & --- & --- & --- & --- & --- & 2.5 \\
\hline SPCD flatness target/I & -3.3 & -4.3 & -7.1 & -9.5 & --- & --- & --- & --- & --- & --- & --- & --- & 0.0 \\
\hline SPCD before compensation/I & -4.1 & -4.8 & -7.9 & -9.3 & --- & --- & --- & --- & --- & --- & --- & --- & 0.9 \\
\hline SPCD after compensation/I & -4.0 & -4.9 & -7.8 & -8.3 & --- & --- & --- & --- & --- & --- & --- & --- & 0.8 \\
\hline
\end{tabular}

wave on the strip profile after annealing, as shown in Figures 8 and 9 . When the wear compensation model is added to the flatness target curve, the flatness deviation $\Delta \sigma_{i}(x)$ caused by wear thickness $h_{i}(x)$ is obtained. It can be seen that the strip is better than the strip profile without compensation curve, as shown in Figures 10 and 11, and there is little edge wave on the strip profile after annealing.

\section{Discussion}

For convenience of calculation, about 330 sets of flatness data are collected for each coil strip along the longitudinal direction of the strip, and these data are sufficient to exhibit strip shape. Too much flatness data will increase the load of computation, resulting in waste of time; too little data cannot show the flatness of strip, increasing calculation error.

The flatness measurement accuracy is not affected if there is uniform wear volume on each measuring ring of the flatness measuring roll. However, the measuring rings in the middle part of the flatness measuring roll are always used to measure the flatness of the strip. The wider the strip is,

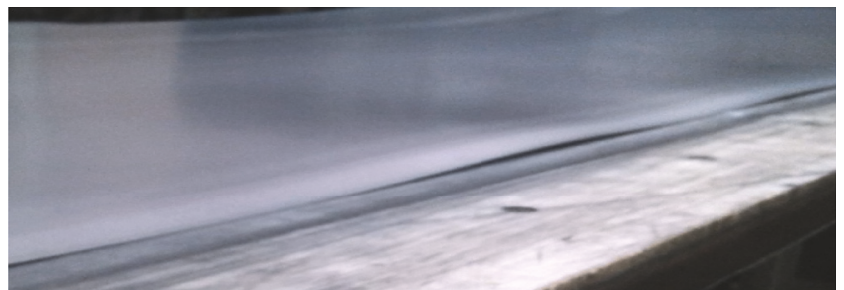

FIGURE 8: The Q195 grade shape quality without wear compensation model after annealing.

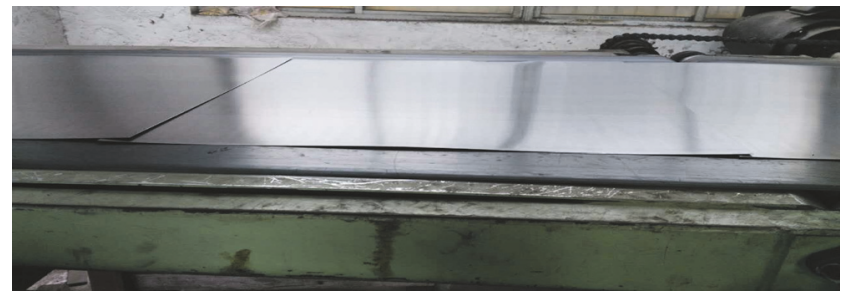

FIGURE 9: The SPCC grade strip shape quality without wear compensation model after annealing. 


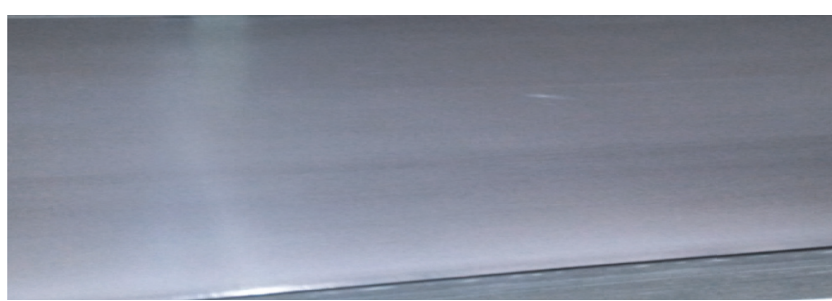

FIGURE 10: The Q195 grade shape quality with wear compensation model after annealing.

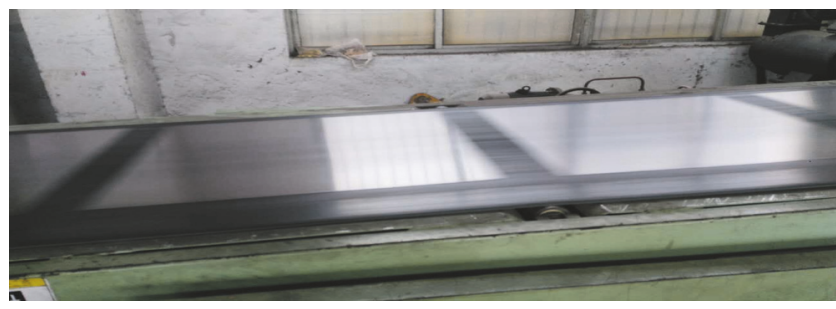

FIGURE 11: The SPCC grade strip shape quality with wear compensation model after annealing.

the more the numbers of the measuring rings are put into use. Whether the measuring rings of the edge of flatness measuring roll are put to use is determined by the width of the strip. When the width of rolled strip is equal to the effective measuring rings width of the flatness measuring roll, the measuring rings of flatness measuring roll are covered by the rolled strip. For example, the narrowest width of the rolled strip is $850 \mathrm{~mm}$, and 14 measuring rings of the $52 \mathrm{~mm}$ wide measuring zone and 4 measuring rings of $26 \mathrm{~mm}$ wide measuring zone are used for measuring the strip flatness. No matter what the width of the strip is, the 14 measuring rings of the $52 \mathrm{~mm}$ wide measuring zone are always put into operation. The wider the width of strip is, the more the numbers of measuring rings are used.

The number of radial forces collected in different intervals is different, and the weighting coefficient is also different. The most important factor is that the width of the rolling strip is different, and the numbers of measuring rings used are different, and the number of radial forces collected for each measuring ring is also different. For example, when the edge measuring rings of flatness measuring roll are not covered by the rolled strip, the corrected times of radial force of the edge measuring rings are zero.

The longer the strip rolling length is, the greater the wear thickness of measuring rings is. Meanwhile, most of the raw materials come from the different factory, and the surface roughness of strip steel is approximately the same. The output of various grades of strip is shown in Table 2. A large number of production strips produce an amount of wear volume of the flatness measuring roll and cannot be ignored.

The radial force distribution of flatness measuring roll is affected by the wear of measuring rings which makes it changed more or less. It can be known that the radial force decreases in the wear serious parts of the measuring rings of the flatness measuring roll and it increases in the slightly wear parts. Under the radial force load, the rolled strip is sufficiently contacted with the flatness measuring roll upper surface, the outermost layer strip length $l_{i}(x)$ between the deflector roll and the coiler should be shortened in the serious wear parts of flatness measuring roll, and the radial force will be decreased and vice versa. The wear compensation curve should be added to flatness target curve if there is a bad strip profile after annealing.

The width and the rolling length of strip have effects on wear thickness of measuring rings, and the deviation between radial forces has little effects on the wear thickness of measuring rings.

\section{Conclusion}

Based on the theory of Archard, definite integral method, and weighted coefficient method, the wear compensation model is established for improving control accuracy in flatness measuring system, which is further used for enhancing the measuring accuracy of the shape control system and strip quality.

The established wear compensation model represents the wear process behavior in precision of flatness measuring roll and provides comparable results about predicted values and actual values. It can be known that the changes in variable values considered in wear compensation model have effects on calculation accuracy.

The wear volume distribution of measuring rings has direct influence on measuring accuracy. The wear compensation values of the flatness measuring roll are obtained after subtracting average radial force of flatness measurement values. Through actual production data of SPCC, Q195, and SPCD grade, the average flatness measurement accuracy is improved by $0.9 \mathrm{I}, 0.5 \mathrm{I}$, and $0.1 \mathrm{I}$. The experiment proves that the wear compensation model plays an important role in improving the shape quality. The industrial application effect is extremely remarkable.

\section{Conflicts of Interest}

The authors declare that they have no conflicts of interest.

\section{Acknowledgments}

The authors acknowledge support by the National Science Technology Support Program of China (Project nos. $61572206,60774028)$.

\section{References}

[1] J.-W. Liu, D.-H. Zhang, and P.-F. Wang, "Research in shape meter roll deflection compensation model," Advanced Materials Research, vol. 146-147, pp. 793-797, 2011.

[2] Y. Peng, H.-M. Liu, and D.-C. Wang, "Simulation of type selection for 6-high cold tandem mill based on shape control ability," Journal of Central South University of Technology (English Edition), vol. 14, no. 2, pp. 278-284, 2007.

[3] A. Aljabri, Z. Y. Jiang, D. B. Wei, X. D. Wang, and H. Tibar, "Thin strip profile control capability of roll crossing and shifting in 
cold rolling mill," Materials Science Forum, vol. 773-774, pp. 7078, 2013.

[4] R. Raghunandan and P. Venkateswara Rao, "Selection of sampling points for accurate evaluation of flatness error using coordinate measuring machine," Journal of Materials Processing Technology, vol. 202, no. 1-3, pp. 240-245, 2008.

[5] U. Ståhlberg and H. Keife, "Improved flatness in cold rolling of copper foils," Journal of Materials Processing Technology, vol. 37, no. 1-4, pp. 157-174, 1993.

[6] J. W. Morris, S. J. Hardy, and J. T. Thomas, "Some fundamental considerations for the control of residual flatness in tension levelling," Journal of Materials Processing Technology, vol. 120, no. 1-3, pp. 385-396, 2002.

[7] H.-M. Liu, X.-L. Zhang, and Y.-R. Wang, "Transfer matrix method of flatness control for strip mills," Journal of Materials Processing Technology, vol. 166, no. 2, pp. 237-242, 2005.

[8] A. S. Malik and R. V. Grandhi, "A computational method to predict strip profile in rolling mills," Journal of Materials Processing Technology, vol. 206, no. 1-3, pp. 263-274, 2008.

[9] B.-Q. Yu, Y.-B. Sun, H.-M. Liu, L. You, and Y. Peng, "Compensation Model for Shape Measuring of Cold Strip Rolling," Journal of Iron and Steel Research, International, vol. 17, no. 6, pp. 21-26, 2010.

[10] X. Cai, D. Zhang, X. Liu, and G. Wang, "Factors Affecting Temperature Distribution Along Thickness of Plate During Cooling Process and Their Control Strategies," Journal of Iron and Steel Research, vol. 17, no. 5, pp. 17-22, 2010.

[11] J.-W. Liu, D.-H. Zhang, J.-S. Wang, and P.-F. Wang, "Deflection Compensation Model for Flatness Measuring Roll," Journal of Iron and Steel Research, International, vol. 17, no. 12, pp. 35-37, 2010.

[12] X.-L. Zhang, S.-Y. Zhang, G.-Z. Tan, and W.-B. Zhao, "A Novel Method for Flatness Pattern Recognition via Least Squares Support Vector Regression," Journal of Iron and Steel Research, International, vol. 19, no. 3, pp. 25-30, 2012.

[13] X.-L. Wen, X.-C. Zhu, Y.-B. Zhao, D.-X. Wang, and F.-L. Wang, "Flatness error evaluation and verification based on new generation geometrical product specification (GPS)," Precision Engineering, vol. 36, no. 1, pp. 70-76, 2012.

[14] H. Pawelski, "Friction inhomogeneities in cold rolling," Journal of Materials Processing Technology, vol. 125-126, pp. 392-397, 2002.

[15] N. F. M. Yusof and Z. M. Ripin, "A technique to measure surface asperities plastic deformation and wear in rolling contact," Wear, vol. 368-369, pp. 496-504, 2016.

[16] M. Ueno, N. Fujita, Y. Kimura, and N. Nakata, "Evaluation of coating and wear characteristics of roll surface coated with TiC by electrical discharge coating," Journal of Materials Processing Technology, vol. 236, pp. 9-15, 2016.

[17] S. Peng and W. Shi, "Adaptive fuzzy integral terminal sliding mode control of a nonholonomic wheeled mobile robot," Mathematical Problems in Engineering, vol. 2017, Article ID 3671846, 2017.

[18] S. F. Javan, S. Abbasbandy, and M. A. F. Araghi, "Application of Reproducing Kernel Hilbert Space Method for Solving a Class of Nonlinear Integral Equations," Mathematical Problems in Engineering, vol. 2017, Article ID 7498136, 2017.

[19] B. Mukanova, T. Mirgalikyzy, and D. Rakisheva, "Modelling the influence of ground surface relief on electric sounding curves using the integral equations method," Mathematical Problems in Engineering, vol. 2017, Article ID 9079475, 10 pages, 2017.
[20] R. Servin-Castañeda, A. M. Garcia-Lara, R. D. Mercado-Solís, and C. A. Vega-Lebrun, "Development of Mathematical Model for Control Wear in Backup Roll for Hot Strip Mill," Journal of Iron and Steel Research, International, vol. 21, no. 1, pp. 46-51, 2014. 


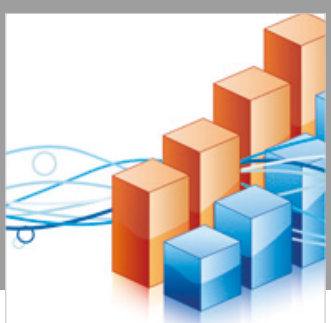

Advances in

Operations Research

\section{-n-m}
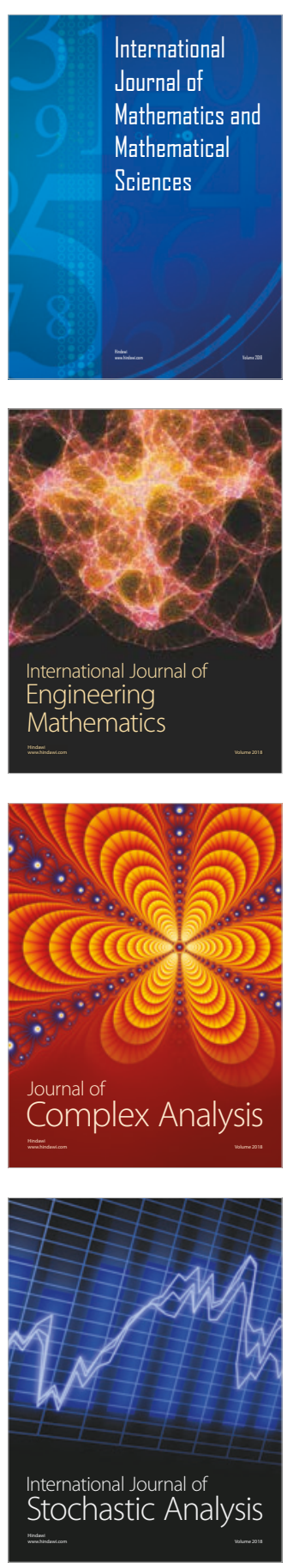
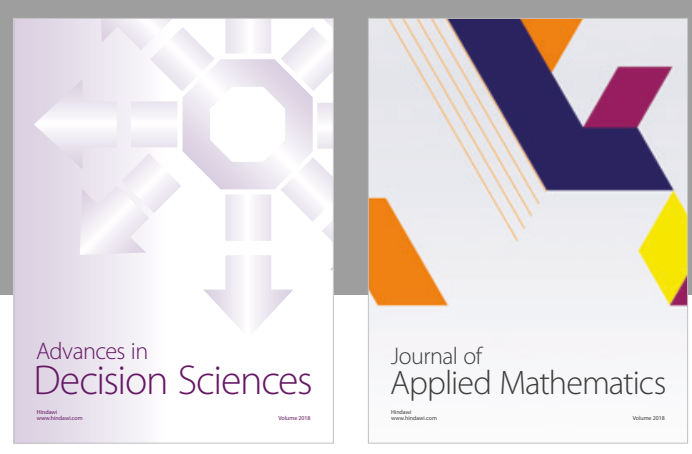

Journal of

Applied Mathematics


Submit your manuscripts at

www.hindawi.com

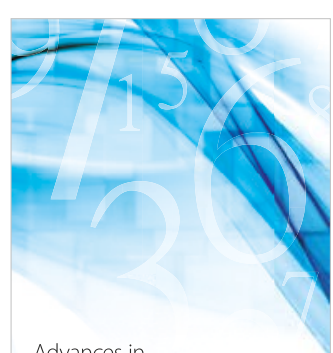

Advances in
Numerical Analysis
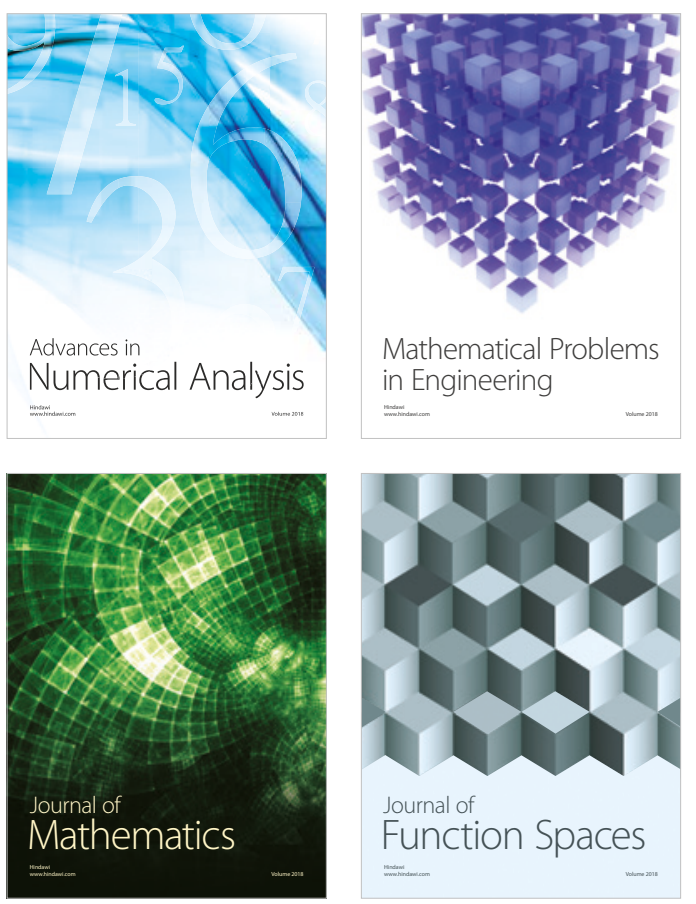

Mathematical Problems in Engineering

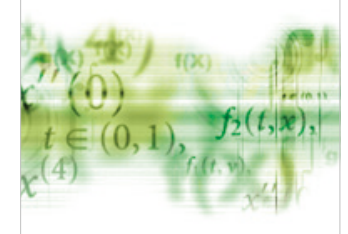

International Journal of

Differential Equations



Journal of

Function Spaces

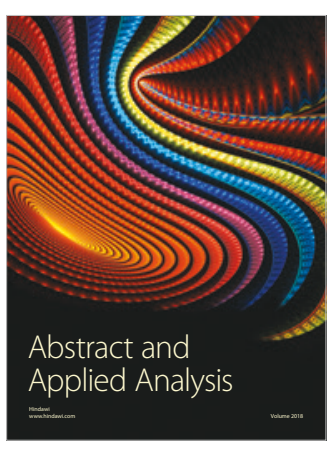

The Scientific

World Journal

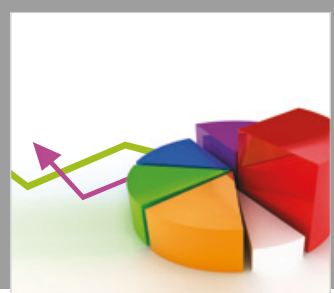

Journal of

Probability and Statistics
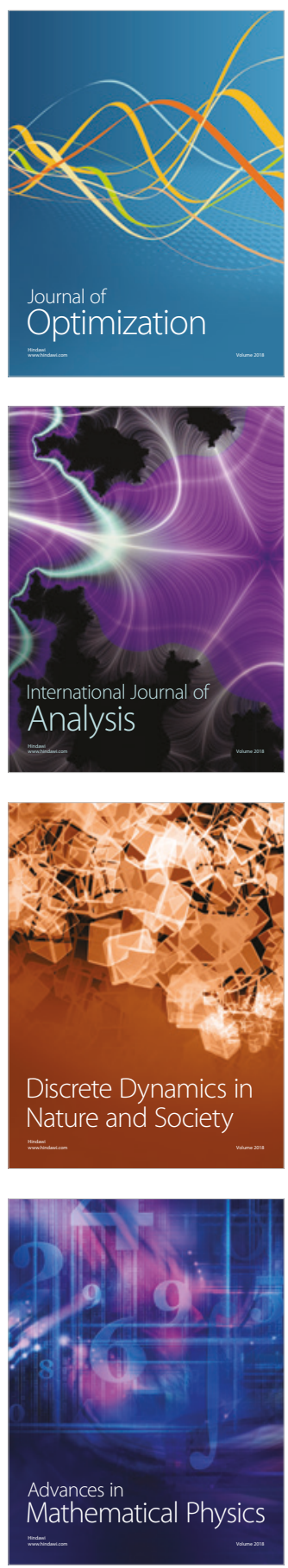